Review

\title{
The Development of Novel Therapies for the Treatment of Acute Myeloid Leukemia (AML)
}

\author{
Sarit Assouline ${ }^{1, *}$, Eftihia Cocolakis ${ }^{1}$ and Katherine L. B. Borden ${ }^{2, *}$
}

1 Department of Medicine and Oncology, Segal Cancer Centre, Jewish General Hospital, Montreal, QC, H3T 1E2, Canada; E-Mail: ecocolakis@jgh.mcgill.ca

2 Department of Pathology and Cell Biology, Institute of Research in Immunology and Cancer (IRIC), Université de Montréal, Pavillion Marcelle-Coutu, Chemin Polytechnique, Montreal, QC, H3T 1J4, Canada

* Authors to whom correspondence should be addressed; E-Mails: Sarit.Assouline@mcgill.ca (S.A.); Katherine.Borden@umontreal.ca (K.L.B.B.); Tel.: +1-514-340-8207 (S.A.); Fax: +1-514-340-8733 (S.A.); Tel.: +1-514-343-6291 (K.L.B.B.); Fax: +1-514-343-7379 (K.L.B.B.).

Received: 22 August 2012; in revised form: 29 September 2012 / Accepted: 17 October 2012 / Published: 2 November 2012

\begin{abstract}
Acute myeloid leukemia (AML) is nearly always a fatal malignancy. For the past 40 years, the standard of care remains a combination of cytarabine and an anthracycline known as $7+3$. This treatment regimen is troubled by both low survival rates $(10 \%$ at 5 years) and deaths due to toxicity. Substantial new laboratory findings over the past decade have identified many cellular pathways that contribute to leukemogenesis. These studies have led to the development of novel agents designed to target these pathways. Here we discuss the molecular underpinnings and clinical benefits of these novel treatment strategies. Most importantly these studies demonstrate that clinical response is best achieved by stratifying each patient based on a detailed understanding of their molecular abnormalities.
\end{abstract}

Keywords: acute myeloid leukemia; targeted therapies; early phase trials

\section{Introduction}

Traditionally, therapies for AML have relied on the use of non-targeted cytotoxic agents, which are often not well tolerated and leave much room for improvement in terms of clinical response. The greatest 
strides in treating myeloid malignancies have come from the development of targeted agents. These include all trans-retinoic acid and arsenic trioxide in acute promyelocytic leukemia, which overcome the differentiation block at the promyelocyte stage by targeting the retinoic acid receptor-associated translocation [1]. Similarly, imatinib mesylate and second and third generation tyrosine kinase inhibitors (TKI) have drastically changed the outlook for patients with chronic myeloid leukemia, by inhibiting the constitutively active bcr-abl protein [2].

Other than these few therapeutic successes, there have been few clinical advances in the treatment of myeloid malignancies, and in particular AML. The standard treatment option for the majority of young, fit patients with AML remains continuous infusion of cytarabine for days 1 to 7 and an anthracycline, daunorubicin or idarubicin, as a daily bolus for days 1 to $3(7+3)$, a long-lived standard combination in use for at least the last 40 years [3]. However, one recent noteworthy development has been the observation based on two large intergroup studies [4,5] that an increased dose of daunorubicin is associated with improved survival. In the ECOG study, which focused on younger patients with AML, this benefit was restricted to those with favorable and intermediate cytogenetics [4]. In the HOVON study, which tested increased doses of daunorubicin in patients aged 60 and older, higher response rates and overall survival was observed in patients aged 60 to 65 and not older, as well as among patients with core-binding factor leukemias [5]. Still, the median overall survival at 2 years ranges from 38 to $50 \%$ for patients receiving higher dose daunorubicin, depending on the age group $[4,5]$.

Many elderly patients, who comprise more than half of those with AML, are unfit for any induction chemotherapy or likely not to benefit due to poor cytogenetic risk [3]. For these patients, the only therapy of demonstrated benefit in the setting of a Phase III trial is low-dose cytarabine. In the Medical Research Council study by Burnett and colleagues, this treatment was associated with a complete response (CR) rate of $18 \%$ and median survival of 80 weeks [6]. Given the low response rates and median survival, this standard is not universally accepted or employed [7].

Novel targeted therapies are needed to improve survival for more patients with AML. Numerous agents are in development with the aim of targeting both well established and more recently identified leukemogenic pathways. This review begins with a discussion of some promising novel targeted agents recently tested in AML patients and, within this context, the clinical hurdles to drug development in AML are highlighted. Non-targeted, conventional chemotherapeutic agents and combinations of these agents remain outside the scope of this review.

\section{Molecular Targets of New Drug Development in AML}

\subsection{Gene Mutations}

While the development of novel therapies has been slow, the knowledge of mutations associated with AML has increased dramatically in recent years. There are known translocations e.g., t(15;17), $\mathrm{t}(8 ; 21)$, inv $16, \mathrm{t}(16 ; 16)$ which are associated with a favorable prognosis; e.g., $\mathrm{t}(15 ; 17), \mathrm{t}(8 ; 21)$, inv 16 , $\mathrm{t}(16 ; 16)$, the so-called core binding factor (CBF) leukemias [8,9]. It is also well established that a complex karyotype (three or more cytogenetic abnormalities) [8,9] and a monosomal karyotype are associated with a poor outcome [10,11]. Finally, numerous, recurrent genetic mutations have been 
shown to predict for survival in patients with cytogenetically normal AML treated with $7+3$ [12]. In one large ECOG study, 97.3\% of AML patients had at least one identifiable mutation (that is, one occurring in greater than $5 \%$ of patients), regardless of the presence of cytogenetic abnormalities [13]. A detailed algorithm was devised to predict survival after $7+3$ based on the combination of the expression of seven genes, including the well known internal tandem duplication of FLT3 and mutations of nucleophosmin (NPM1). Furthermore, survival was improved among patients with DNA methyl transferase 3A (DNMT3A) or NPM1 mutations or mixed lineage leukemia (MLL) translocations when higher doses of daunorubicin were employed [13]. Subdividing patients who can benefit from higher doses of chemotherapy on the basis of gene mutations is a step in the direction of personalized therapy for AML, but still does not make full use of the clearly identified molecular heterogeneity of AML.

Mechanisms of leukemogenesis have been attributed to many of the known mutations, but most have not been the subject of a targeted therapeutic plan. This may be due to: (1) a lack of identified therapies to target the mutations; (2) the genetic complexity of AML which is often characterized by several co-existing mutations that all contribute to leukemogenesis; and, (3) low numbers of patients with any given mutation, which makes it difficult to devise a clinical trial with a reasonable accrual rate. For example, c-kit mutations have been described in CBF leukemias [14,15]. However, despite the presence of c-kit inhibitors, results with these have never been reported, perhaps because this subgroup represents a relatively small number of patients. However, given the frequency of FLT3-ITD mutations in AML and the existence of inhibitors, this gene mutation has been targeted. The exception, of course, includes therapies targeting FLT3-ITD.

The most promising target for AML therapy in this past decade has been the FLT3 (FMS-like tyrosine kinase 3) protein. FLT3 is a transmembrane receptor tyrosine kinase that belongs to the same family as FMS, kit, and PDGFRa/b. It is mutated in about $30 \%$ of all AML [16]. The mutations include in-frame internal tandem duplication (ITD) of the transmembrane domain in $95 \%$ of cases, and a tyrosine kinase domain (TKD) mutation at aspartic acid residue 835 in the remainder, with other mutations rarely observed [17]. For AML patients with normal cytogenetics, the presence of an FLT3 ITD mutation, is associated with poorer progression-free and overall survival [12].

In AML, there is constitutive activation of FLT3 either due to interference with the negative regulatory function of the juxtamembrane region with ITD mutations, or changes in the activation loop with TKD mutations [18]. As a result, there is autophosphorylation and direct or indirect phosphorylation of several proteins that, in turn, activate the PI-3-kinase/AKT, RAS/MAPK, and STAT5 pathways, ultimately inducing cellular proliferation and inhibiting apoptosis [19]. Interestingly, isolation of FLT3-mutated human CD34+CD38- leukemia stem cells indicated that all had the FLT3 mutation, and, injection of these cells into NOD/SCID mice resulted in leukemogenesis that was entirely FLT3 mutated [20]. Thus, FLT3 mutations can drive leukemogenesis. Clinical evidence suggests that the FLT3 mutation may occur in a sub-clone of the leukemia stem cell (LSC), including the finding that in the context of relapsed AML, there is loss of the ITD mutation $16 \%$ of the time and loss of the TKD mutation $50 \%$ of the time $[21,22]$.

Given these data and the availability of several TKIs with activity against FLT3-mutated leukemia [23], several clinical trials have been undertaken. There are multi-targeted TKI with activity against FLT3, including lestaurtinib, midostaurin and sorafenib; and, more specific inhibitors of FLT3, quizartinib 
and tandutinib. As single agents, all exhibit some anti-leukemia activity, but the development of tandutibin has been limited by its toxicity profile [23]. The multi-targeted agents have activity in AML with wild-type FLT3, but activity is greater in the presence of FLT3 ITD or TKD (Table 1).

Table 1. Representative single agent activity of targeted therapies in AML.

\begin{tabular}{|c|c|c|c|c|c|}
\hline Treatment & $\begin{array}{l}\text { Complete } \\
\text { response \% }\end{array}$ & $\begin{array}{l}\text { Partial } \\
\text { response \% }\end{array}$ & Blast response \% & Comments & Ref. \\
\hline \multicolumn{6}{|l|}{ FLT3 inhibitors } \\
\hline $\begin{array}{l}\text { Sorafenib } \mathrm{n}=50 ; \mathrm{n}=39 \text { with } \\
\text { FLT3 ITD or D } 835 \text { point } \\
\text { mutation or both }\end{array}$ & $\begin{array}{l}10 \%(13 \% \\
\text { FLT3 } \\
\text { mutation })\end{array}$ & & $\begin{array}{l}34 \% \text { (all with } \\
\text { FLT ITD) }\end{array}$ & $\begin{array}{l}\text { Phase I, } \\
\text { relapsed/refractory } \\
\text { AML }\end{array}$ & {$[24]$} \\
\hline $\begin{array}{l}\text { Midostaurin } \mathrm{n}=95 ; \mathrm{n}=35 \\
\text { FLT mutant }\end{array}$ & 0 & $1.6 \%$ & $\begin{array}{l}71 \% \text { FLT3 ITD } \\
42 \% \text { FLT3 WT }\end{array}$ & $\begin{array}{l}\text { Phase II, } \\
\text { relapsed/refractory } \\
\text { MDS and AML }\end{array}$ & {$[25]$} \\
\hline Lestaurtinib $n=14$ & $0 \%$ & $0 \%$ & $29 \%$ & $\begin{array}{l}\text { Phase II, } \\
\text { relapsed/refractory } \\
\text { AML with FLT3 ITD }\end{array}$ & [26] \\
\hline $\begin{array}{l}\text { Lestaurtinib } n=5 \text { with FLT } 3 \\
\text { mutation } n=22 \mathrm{WT}\end{array}$ & 0 & 0 & $\begin{array}{l}60 \%(\text { FLT3 } \\
\text { mutated) } 23 \% \\
(\mathrm{WT}) \\
\end{array}$ & $\begin{array}{l}\text { Phase II, newly } \\
\text { diagnosed AML in the } \\
\text { elderly }\end{array}$ & {$[27]$} \\
\hline $\begin{array}{l}\text { AC220 } n=76 ; n=47 \text { with } \\
\text { FLT3 mutant }\end{array}$ & $\begin{array}{l}12 \%(22 \% \text { flt } 3 \\
\text { mutated; } 6 \% \\
\text { WT; } 18 \% \text { unk })\end{array}$ & $\begin{array}{l}18 \%(33 \% \text { flt } 3 \\
\text { mutated; } 13 \% \\
\text { WT; } 18 \% \text { unk })\end{array}$ & & $\begin{array}{l}\text { Phase I, relapsed } \\
\text { refractory AML } \\
\text { unselected for FLT3 } \\
\text { ITD }\end{array}$ & {$[28]$} \\
\hline \multicolumn{6}{|l|}{ Epigentic modulation } \\
\hline 5-azacytidine $n=113$ & $\begin{array}{l}18 \%(v s .16 \% \\
\text { in BSC) }\end{array}$ & & & $\begin{array}{l}\text { Subanalysis of patients } \\
\text { with low blast count in } \\
\text { phase III trial }\end{array}$ & {$[29]$} \\
\hline Decitabine $\mathrm{n}=485$ & $\begin{array}{l}17.8 \%(\mathrm{vs} .7 .8 \% \\
\text { conventional } \\
\text { care })\end{array}$ & & & $\begin{array}{l}\text { Phase III trial compared } \\
\text { to conventional care } \\
\text { (TC) AML }\end{array}$ & {$[30]$} \\
\hline \multicolumn{6}{|c|}{ mRNA processing and translation } \\
\hline Ribavirin $\mathrm{n}=11$ & $7 \%$ & $13 \%$ & $27 \%$ & $\begin{array}{l}\text { AML FAB M4 and M5 } \\
\text { M4 and M5 subtypes, } \\
\text { phase II, refractory, } \\
\text { relapsed or newly } \\
\text { diagnosed, unfit for } \\
\text { induction chemotherapy }\end{array}$ & {$[31]$} \\
\hline \multicolumn{6}{|l|}{ PI3K/Akt/mTOR } \\
\hline $\begin{array}{l}\text { Deformolus (Rapamycin } \\
\text { analogue) } n=22\end{array}$ & $0 \%$ & $0 \%$ & $0 \%$ & Phase II & {$[32]$} \\
\hline \multicolumn{6}{|l|}{ Protein recycling } \\
\hline Tosedostat $\mathrm{n}=73$ & $12 \%$ & $10 \%$ & & $\begin{array}{l}\text { Phase II, patients aged } \\
60 \text { and over with } \\
\text { relapsed, refractory } \\
\text { disease }\end{array}$ & {$[33]$} \\
\hline
\end{tabular}


Table 1. Cont.

\begin{tabular}{|c|c|c|c|c|c|}
\hline Treatment & $\begin{array}{l}\text { Complete } \\
\text { response \% }\end{array}$ & $\begin{array}{l}\text { Partial } \\
\text { response \% }\end{array}$ & Blast response \% & Comments & Ref. \\
\hline \multicolumn{6}{|l|}{ CD33 } \\
\hline $\begin{array}{l}\text { Gemtuzumab ozogamycin } \\
\mathrm{n}=142\end{array}$ & $29 \%$ & & $17 \%$ & $\begin{array}{l}\text { Phase II; relapsed } \\
\text { AML; complete } \\
\text { response includes } \\
\text { patients with } \\
\text { incomplete platelet } \\
\text { recovery }\end{array}$ & [34] \\
\hline \multicolumn{6}{|c|}{ Farnesylation and RAS targeting } \\
\hline $\begin{array}{l}\text { Farnesyl Transferase Inhibitor } \\
\text { R115777 n }=34\end{array}$ & $6 \%$ & $24 \%$ & & $\begin{array}{l}\text { Phase II; relapsed/ } \\
\text { refractory AML }\end{array}$ & [35] \\
\hline
\end{tabular}

$\mathrm{WT}=$ wild type unk $=$ unknown mutational status; $\mathrm{BSC}=$ best supportive care.

There have been several reasons identified for the limited success of FLT3 inhibitors. The problem of bioavailability has been highlighted by a randomized Phase III trial of induction chemotherapy combined with lestaurtinib in relapsed AML with FLT3-ITD, where there was no improvement in survival over chemotherapy alone. This was attributed to decreasing plasma levels of lestaurtinib with time, and increasing alpha-1 acid glycoprotein, which binds lestaurtinib in vivo [36]. In addition, in vitro studies indicate that samples with high FLT3-ITD allele burden are more sensitive to the cytotoxic effect of FLT3 inhibitors compared to samples with a low allele burden [21,37]. FLT3 upregulation has also been observed in vivo following exposure to lestaurtinib [27]. Finally, recent compelling data indicate that immunosuppresive therapy, including chemotherapy, increases circulating levels of FLT3 ligand, which may reduce the ability of TKIs to inhibit FLT3 activity [38]. Nonetheless, there is an ongoing Phase III clinical trial testing midostaurin with induction chemotherapy in newly diagnosed AML with FLT3-ITD (clinicaltrials.gov NCT00651261). If results of this trial are positive, they will dramatically change the treatment of newly diagnosed AML with FLT3 mutation. It may be that using these agents in the frontline setting will allow for greater efficacy.

\subsection{Epigenetic Changes}

Anomalous epigenetic changes, including DNA hypermethylation and histone acetylation/deacetylation occur frequently in acute leukemia. The recurring chromosomal translocations seen in AML lead to the generation of chimeric fusion oncoproteins e.g., TEL-AML, AML-ETO, PML-RARa, etc. In many cases these fusion proteins contribute to the development of leukemia partly by disrupting the modification of chromatin, through recruitment of chromatin-modifying coregulators [39]. In AML, aberrant $\mathrm{CpG}$ island hypermethylation of tumor suppressor genes leads to transcriptional shut-down and involves the recruitment of methyl-binding proteins and histone deacetylases (HDACs) to regions near transcription start sites [40,41]. Unlike chromosomal deletions that lead to an irreversible loss of function, transcriptional repression by epigenetic mechanisms such as histone deacetylation and promoter DNA methylation can be reversed using HDAC inhibitors (HDACi) and hypomethylating agents, respectively. These compounds are effective at controlling leukemic cell growth in the 
laboratory. The cytidine analogs 5-aza-2'-deoxycytidine (decitabine) and 5-azacytidine can reactivate tumor suppressor genes silenced by promoter hypermethylation [42]. Incorporation of these agents into DNA leads to subsequent DNA demethylation via their irreversible inhibition of DNMTs. Importantly, many of these compounds have other functions as well, e.g., azacytidine is incorporated into nearly all forms of RNA [43-45], and the contribution of these has not been well studied.

Clinically, 5-azacytidine treatment leads to improved overall survival in AML patients with low blast counts, as demonstrated in a sub-analysis of the AZA-001 study of high risk myelodysplastic syndrome, in which approximately one third of patients had low blast count AML [30]. When decitabine, a 5-azacytidine pro-drug, was compared to best supportive care in a Phase III trial of AML, there was no survival benefit in patients receiving decitabine over the control arm at the planned analysis point. But, the data were analyzed one year later, at which point a small survival advantage of 2 months became statistically significant ( $p=0.037$ ). A reason for the modest benefit was that patients with high percentage blast count and high white counts were included in this study. This was in contrast to the patients enrolled in the AZA-001 study, who had low white counts and blast counts not exceeding 30\% [31]. Finally, unique subtypes of AML have been identified on the basis of DNA methylation signatures, which were found to be predictive of survival but not yet of response to hypomethylating agents [46]. HDACi have been tested in AML with modest results [47]. Combinations of HDACi with DNA hypomethylating agents have been reported [48,49] or are underway. Such combinations are appealing, as these epigenetic modes of regulation cooperate. However, so far, they have not yielded high response rates.

\section{3. $m R N A$ Processing and Translation}

Messenger RNA (mRNA) processing and mRNA translation are important steps in the regulation of protein levels in cells and these processes are coupled to essential cellular events such as growth, proliferation, differentiation and apoptosis. In normal hematopoietic cells, translation of transcripts into protein is tightly regulated at the initiation phase by signal transduction pathways including PI3K/AKT pathways that can ultimately affect eukaryotic translation initiation factor 4E (eIF4E). Most AMLs are characterized by elevated PI3K and Akt activity [50,51]. Further, eIF4E levels themselves become highly elevated in the M4 and M5 subset of AML at both the RNA and protein levels [32,52-54]. Additionally, eIF4E is highly concentrated in the cell nucleus in these cells [32,52-54]. Elevated eIF4E levels and activity increase translational initiation for a subset of mRNAs and thereby enable multiple ribosomes to translate the same transcript simultaneously. In this way, eIF4E increases translational efficiency of a specific subset of transcripts that are associated with proliferation and survival signaling. Further, eIF4E enhances the mRNA export of a subset of transcripts also involved in proliferation and survival which increases their cytoplasmic levels and thus their availability to the translation machinery. Both of these activities are stimulated by the phosphorylation of eIF4E which occurs via Mnk kinase [55-59]. Thus, targeting PI3K, Akt, Mnk and eIF4E are all reasonable strategies to target these processes.Cancer cells appear to develop an oncogene addiction to eIF4E thereby providing a therapeutic window for targeting this protein [32,60,61].

The only direct approach to target eIF4E in AML patients in the clinic thus far has been with ribavirin $[52,32,60,62]$. Ribavirin is a well-characterized broad spectrum nucleoside analogue with 
antiviral activity against a range of viruses [52]. Ribavirin can act as competitive inhibitor of the natural ligand of eIF4E, the methyl 7 guanosine cap. Consistently, ribavirin targets eIF4E directly in a variety of systems, thereby inhibiting translation and/or mRNA export of sensitive transcripts. A small phase II clinical trial examining the efficacy of ribavirin treatment in refractory, relapsed or unfit for chemotherapy M4 and M5 AML patients demonstrated clinical activity and associated molecular responses. Out of 11 patients, three achieved a partial or complete response and three had blast responses [32]. Common leukemia drugs such as ara-C and idarubicin combine with ribavirin to further reduce colony number in primary patient specimens ex vivo [53] and served as the starting point for a phase I trial in M4/M5 AML with patients using ribavirin in combination with low dose ara-C (ClinicalTrials.gov NCT01056523) [63].

\subsection{PI3/AKT/mTOR Pathways}

Most AML cells show activated PI3K/AKT/mTOR pathways [50,51]. For example, the Carroll laboratory showed that PI3 kinase inhibitors such as LY294002, or the more specific inhibitor PI-103, induced cell death in primary AML cells ex vivo [64,65]. Akt activation assays confirmed that Akt activity was high in most specimens. Inhibition of Akt with perfosine, which affects other kinases as well [66], in preclinical studies suggested that combining this with MEK inhibitors kill AML cells ex vivo [67]. There is an ongoing clinical trial to test this hypothesis using perifosine and UCN-1 (Clinicaltrials.gov NCT00301938).

Downstream of PI3K and AKT is the mTOR pathway. mTOR activation results in the phosphorylation of both eIF4E binding protein BP1 and ribosomal S6 protein. In AML, S6 phosphorylation is a robust marker (see below). Early studies with rapamycin, an mTORC1 inhibitor, failed to show responses in clinical trial as a single agent [68]. However, it may play a role as a chemosensitizing agent [69]. Combinations of chemotherapy with PI3K and TORC1/2 inhibitors could achieve clinical responses superior to either agent alone $[33,70]$. Supporting this idea, the combination of one rapalogue, temsirolimus, with clofarabine in elderly high risk AML patients showed an overall response rate of $21 \%$ which was comparable to single agent clofarabine [71]. However, there was a much more substantial $75 \%$ response rate in the 12 patients that demonstrated inhibition of S6 phosphorylation [71]. One of the most robust markers of mTOR signaling in AML is phosphorylation of the S6 protein which is readily observed by flow cytometry in primary patient specimens and thus can be used as a molecular marker for drugs that target this pathway [36]. Interestingly, less than 50\% of cells show S6 activation at any given time in primary AML specimens ex vivo [36]. This heterogeneity could arise due to differences in drivers of oncogenesis and/or differences related to cell cycle status. In a sirolimus plus chemotherapy trial of refractory and relapsed AML patients, again there was a striking correlation between ribosomal S6 phosphorylation and response [72].

\subsection{Protein Recycling}

Tosedostat is an inhibitor of aminopeptidase and therefore acts by depleting amino acids. In the HL-60 leukemia cell line, gene array studies have shown that this amino acid depletion resembles an amino acid deprivation response (AADR) [73]. In the same cell line model, tosedostat also inhibits phosphorylation of mTOR substrates and reduces protein levels, both of which are indicative of amino 
acid depletion, and leads to increased concentrations of intracellular small peptides [73]. By blocking protein recycling, tosedostat likely depletes sensitive tumor cells of amino acids thereby generating an antiproliferative effect.

In a phase II study of tosedostat as a single agent in elderly patients with relapsed AML, median age 72 , and half with refractory disease prior to starting therapy, $12 \%$ had a complete response and $10 \%$ a partial response. Some of these responses occurred among patients having failed hypomethylating agents and patients who had MDS previously. The median survival among patients with a CR was 323 days, 195 days among patients with partial response, and 162 days in those with stable disease [34]. Based on these promising results, a phase III study is planned in patients with high risk MDS and AML who have failed therapy with a hypomethylating agent.

\subsection{Monoclonal Antibody Therapy against CD33: Gemtuzumab Ozogomycin}

Monoclonal antibody therapy has proven extremely successful in other malignancies. In AML, gemtuzumab ozogomycin (GO) is an antibody-drug conjugate where a humanized monoclonal IgG4 antibody directed against CD33 is linked to a derivative of calicheamicin, a potent DNA-binding cytotoxic antibiotic [74]. CD33 antigen is expressed on leukemic myeloblasts in approximately $90 \%$ of patients, making GO an attractive anti-leukemic therapy [75]. In fact, GO was granted approval by the FDA in 2000 for the treatment of relapsed CD33-positive AML patients that were not considered candidates for cytotoxic chemotherapy and were over the age of 60 based on three open label trails showing a $30 \%$ complete response rate and favorable safety profile [35,76]. However, results from Phase III combination trials have provided mixed outcomes in first-line AML patients. The FDA required, post-approval SWOG study (S0106) was terminated early after an interim analysis revealed a significantly higher risk of fatal induction adverse events $(5.8 \%$ vs. $0.8 \%)$ and no improvement in complete remission rates, relapse free survival, post-consolidation disease free survival, or overall survival. Untreated AML patients under the age of 61 were randomized to cytarabine and daunorubicin with or without GO $\left(6 \mathrm{mg} / \mathrm{m}^{2}\right)$ [77]. In June 2010, GO was withdrawn from the market because of concerns about safety and lack of efficacy [78].

AML15 compared the addition of GO to one of three induction schedules and/or one of two consolidation schedules [79]. A total of 1,113 AML patients between the ages of 15 and 60 years were randomly assigned to receive GO as part of their induction therapy (daunorubicin and cytarabine; cytarabine, daunorubicin, and etoposide; or fludarabine, cytarabine, granulocyte colony-stimulating factor, and idarubicin) and a total of 948 AML patients of the same age group were randomized to GO with or without consolidation therapy (amsacrine, cytarabine, and etoposide or high-dose cytarabine). There was no significant increase in toxicity noted in the patients on the GO arms. Unfortunately, there was no difference in response and overall survival when GO was added to either induction or consolidation therapy. However, a subset of patients with favorable cytogenetics that received GO as part of their induction regimen showed a significant survival benefit [79]. AML16 examined the addition of GO to induction chemotherapy in patients over the age of 60 [80]. In this case, there was a small improvement in overall survival with the addition of GO. Furthermore, a meta-analysis of both trials indicated a significant improvement in survival overall [80]. 
Finally, a phase III study by Castaigne and colleagues performed in 26 centers in France, evaluated the benefit of low dose GO when added to $7+3$ in newly diagnosed AML patients between the ages of 50 and 70 [81]. A total of 280 patients were randomly assigned to either $7+3$ with or without GO at $3 \mathrm{mg} / \mathrm{m}^{2}$. GO was given on day 1,4 and 7 in order to deliver a cumulative dose of $9 \mathrm{mg} / \mathrm{m}^{2}$ and to reduce liver toxicity. Event free survival at 2 years showed a significant advantage at $41.4 \%$ in patients treated with GO in comparison to $15.6 \%$ for the chemotherapy alone arm. Similarly, there was an overall survival benefit of $53.2 \%$ versus $41.9 \%$ as well as a benefit in relapse free survival of $50.3 \%$ versus $22.7 \%$ in the GO-containing regimen, and no increase in treatment related death [81]. The findings from this trial should spark new interest in GO as a front-line therapy for AML.

\section{Phase II Clinical Trial Design Strategies for New Drug Development in AML}

New drug development relies heavily on the results of Phase II trials, which determine whether a therapy will be tested in large, Phase III trials. Phase II clinical trial design includes not only the method by which patients will be enrolled and the sample size, but also the dose and schedule for single and combination drugs, patient selection, determination of primary and secondary endpoints, and response assessments. This section reviews some of these elements and current difficulties.

\subsection{Clinical Trial Design}

Most phase II trials in AML are single arm, uncontrolled trials with small sample sizes [82] mainly because AML is a relatively rare disease. In the absence of a comparator arm, it is uncertain whether the experimental therapy increases response rates over standard chemotherapy or no therapy at all, this has been a criticism of many AML trials [82]. Having a standard of care as the control arm within the phase II trial design could make such studies more robust.

In order to deal with the small sample sizes and lack of comparator arm, the "Pick-a-Winner" design has been proposed [83]. In this design, patients with AML are enrolled and randomized either to a standard of care, or one of several experimental therapies. These experimental therapies can be added or removed over the life of the trial based on a pre-specified response rate. In this way, novel therapies are compared to a standard, and ineffective therapies can be rejected quickly [83]. However, because of the molecular and clinical heterogeneity of AML, as discussed, this process may erroneously reject an effective therapy. Furthermore, this design assumes access to numerous anti-leukemia therapies which is not always feasible.

\subsection{Designing Combination Agent Trials}

Single agent studies are obviously limited by both low response rates and remission duration. An obvious way to circumvent these problems is to combine them with standard chemotherapeutic drugs known to have activity in AML and, ideally, synergy in vitro with the novel agent. A recent example includes the combination of salvage chemotherapy and plerixafor, an inhibitor of CXCR4, in relapsed and refractory AML [84]. CXCR4 is a cell membrane receptor found on AML blasts and marrow stem cells. It provides a survival signal to these cells when hybridized with its ligand CXCL12, which is produced by marrow stromal cells. Plerixafor is used for stem cell mobilization by inhibiting the 
interaction between marrow stroma and stem cell $[85,86]$. In AML, inhibiting the function of CXCR4 may enhance chemosensitivity by removing the AML blast from its protective environment and also by inhibiting survival signaling through CXCR4 [87]. In mouse models of AML, plerixafor enhances response rates to chemotherapy [87]. On the basis of these data, a phase I/II study was completed in relapsed/refractory patients with AML given mitoxantrone, etoposide and cytarabine (MEC) chemotherapy and plerixafor. Plerixafor successfully mobilized AML blasts, as reported in the study, and the therapy appeared to be safe, not inducing hyperleucocytosis or profound aplasia [84].

In combining targeted agents with chemotherapeutic drugs, toxicity becomes a concern. In the SWOG study of GO and induction chemotherapy, there was excess death in the GO arm attributed to the dose and schedule of GO, whose toxicity may have been enhanced by chemotherapy [77]. When the dosing schedule of GO was changed to deliver lower doses but to maintain an adequate cumulative dose, an advantage was observed in terms of overall survival [81]. In the lestaurtinib plus chemotherapy trial, the sub-optimal pharmacokinetics of lestaurtinib and the upregulation of FLT3 ligand by chemotherapy likely contributed to the negative results [36]. Finally, when examining the serum steady state levels of ribavirin in combination with low dose cytarabine, they were lower among patients given cytarabine compared to those given ribavirin alone leading to dose escalation of ribavirin in order to achieve appropriate plasma levels, and this was associated with clinical responses including remissions [63]. As can be seen, combining novel agents with chemotherapy in AML is challenging and requires consideration of altered pharmacokinetics, which can affect both toxicity and response rates.

One sophisticated approach to ensuring greater predictability in drug delivery is exemplified by the development of CPX-351, a liposomal preparation of cytarabine and daunorubicin, which maintains a fixed ratio of 5:1 cytarabine:daunorubicin. This preparation has shown promise in a small randomized Phase II trial of older patients with newly diagnosed AML. By maintaining a fixed ratio of drugs, CPX-351 maximizes synergy and minimizes antagonism in vitro. In clinical trials, the fixed ratio is maintained [88], and in Phase II testing, in comparison to standard $7+3$, CPX-351 induces more complete responses, and is associated with less induction mortality and an improvement in overall survival [89]. How this technology can be applied more generally remains to be seen.

\subsection{Impact of Patient Factors in Clinical Trial Design}

An important consideration in the development of new therapies for AML is the selection of patients for Phase I and II trials. For the majority of trials, these are patients with relapsed AML or elderly patients for whom induction chemotherapy is not feasible. These are important populations to target given the dearth of therapeutic options. However, these patients are often more frail, less able to tolerate chemotherapy and have a more resistant and more genetically heterogeneous disease than young, newly diagnosed patients.

From our experience with Phase I and II trials in AML, the early attrition rate due to rapid disease progression, infection, or overall clinical deterioration approaches 33\%. Such a high rate of early attrition could result in a therapy being falsely determined to be ineffective if all patients having taken at least one dose of treatment are considered evaluable for response. 
Further, difficulties in testing new drugs in refractory and relapsed AML patients include the development of drug resistance mechanisms (including $p$-glycoprotein and other mechanisms) that affect not only standard agents, but also the novel therapeutics. For instance, if drug transporters are downregulated as a response to one therapy, all therapies requiring this drug transporter, despite being based on different intracellular pathways, would be expected to fail. This leads to a conundrum in using heavily pretreated patients in these studies as drugs effective as first line agents may fail in this setting.

Another common issue in clinical trials of agents without a rapid rate of response, which is the case for many novel agents, has been that patients with a high peripheral blood blast count, or rapidly doubling white count are less likely to respond [31]. Some groups have used the strategy of selecting patients with leucopenia and slow white count doubling time for their trials in order to allow time for therapies to work $[34,90]$. Alternatively, combinations with more aggressive chemotherapy can help to decrease blast counts quickly to allow the targeted agent time to act on the remaining leukemic cells.

\subsection{Using Molecular Correlates to Design Clinical Trials}

As with other cancers, a detailed understanding of the molecular profile of a particular AML is needed to appropriately place individuals on suitable clinical trials. Mutational testing is a first step in identifying potential targets and in selecting therapies, but, as can be seen from the FLT 3 inhibitor data, targeting a single mutation is likely insufficient. In addition, other molecular predictors of response characterize certain AMLs, including eIF4E overexpression in AML FAB subtypes M4 and M5. In the proof-of-principle trial, responses to ribavirin were seen irrespective of FLT3 mutation status [32]. As discussed, S6 phosphorylation is a predictor of response to mTOR inhibitors [71,72]. Finally, gene signatures, as determined by gene expression profiling, can predict for response to certain therapies. An example includes the combination of tipifarnib and etoposide. Tipifarnib alone has limited activity in elderly patients with newly diagnosed AML [91], however when combined with etoposide, response rates are higher and, more importantly, patients with a particular two gene signature have a significantly higher response rate [90]. Added to that, data indicate that adequate inhibition of target is associated with a better response rate [36]. This suggests that studies should not only assess target inhibition but should respond to inadequate inhibition with intrapatient dose escalation, toxicity permitting.

\section{Conclusions}

Some of the most relevant pathways and mutations in AML have been outlined, as well as the therapies being developed to target these pathways. No single molecular abnormality accounts for leukemogenesis in AML and given this complexity, it is not surprising that targeted agents have not led to widely applicable therapies. However, some of these agents, even as monotherapies have been associated with activity including some complete responses, when the most apt patient cohorts are considered (Table 1). How best, then, to utilize the plethora of both laboratory and clinical information to enhance the effectiveness of AML therapies in the future? Rejecting any given therapy based on a lack of overall benefit in Phase III testing is too drastic an approach in the context of a disease where there is so much molecular complexity, and where therapies likely to have an impact will benefit only specific subgroups of patients as has been demonstrated by several examples provided here. Along the 
same vein, allowing therapies to enter Phase III testing, where hundreds of patients are to be enrolled, without refining the patient selection process based on the likelihood of responding, seems not only wasteful of our acquired collective knowledge, but, more importantly, of our patients' precious time and wellbeing. While this may affect the rate of accrual, particular attention to patient selection for trial entry, based on molecular variables, in particular, but also on clinical variables, can make the difference between identification to a therapy which can provide benefit to some patients with AML rather than no benefit to anyone.

\section{Acknowledgements}

We are grateful for the financial support from the NIH and the LLS USA. KLBB holds a Canada Research Chair. IRIC receives infrastructure support from the FRSQ and CIHR. SA holds an FRSQ Clinician Scientist Award.

\section{References}

1. Baljevic, M.; Park, J.H.; Stein, E.; Douer, D.; Altman, J.K.; Tallman, M.S. Curing all patients with acute promyelocytic leukemia: Are we there yet? Hematol. Oncol. Clin. North Am. 2011, 25, 1215-1233.

2. Smith, C.C.; Shah, N.P. Tyrosine kinase inhibitor therapy for chronic myeloid leukemia: Approach to patients with treatment-naive or refractory chronic-phase disease. Am. Soc. Hematol. Educ. Program 2011, 2011, 121-127.

3. Martin, M.G.; Abboud, C.N. Induction therapy for elderly patients with acute myeloid leukemia. Blood Rev. 2008, 22, 311-320.

4. Fernandez, H.F.; Sun, Z.; Yao, X.; Litzow, M.R.; Luger, S.M.; Paietta, E.M.; Racevskis, J.; Dewald, G.W.; Ketterling, R.P.; Bennett, J.M.; et al. Anthracycline dose intensification in acute myeloid leukemia. N. Engl. J. Med. 2009, 361, 1249-1259.

5. Lowenberg, B.; Ossenkoppele, G.J.; van Putten, W.; Lowenberg, B.; Ossenkoppele, G.J.; van Putten, W.; Schouten, H.C.; Graux, C.; Ferrant, A.; Sonneveld, P.; et al. High-dose daunorubicin in older patients with acute myeloid leukemia. N. Engl. J. Med. 2009, 361,1235-1248.

6. Burnett, A.K.; Milligan, D.; Prentice, A.G.; Goldstone, A.H.; McMullin, M.F.; Hills, R.K.; Wheatley, K. A Comparison of low-dose cytarabine and hydroxyurea with or without all-trans retinoic acid for acute myeloid leukemia and high-risk myelodysplastic syndrome in patients not considered fit for intensive treatment. Cancer 2007, 109, 1114-1124.

7. Burnett, A.; Wetzler, M.; Lowenberg, B. Therapeutic advances in acute myeloid leukemia. J. Clin. Oncol. 2011, 29, 487-494.

8. Slovak, M.L.; Kopecky, K.J.; Cassileth, P.A.; Harrington, D.H.; Theil, K.S.; Mohamed, A.; Paietta, E.; Willman, C.L.; Head, D.R.; Rowe, J.M.; et al. Karyotypic analysis predicts outcome of preremission and postremission therapy in adult acute myeloid leukemia: A Southwest Oncology Group/Eastern Cooperative Oncology Group Study. Blood 2000, 96, 4075-4083. 
9. Grimwade, D.; Walker, H.; Oliver, F.; Wheatley, K.; Harrison, C.; Harrison, G.; Rees, J.; Hann, I.; Stevens, R.; Burnett, A.; et al. The importance of diagnostic cytogenetics on outcome in AML: Analysis of 1,612 patients entered into the MRC AML 10 trial. The Medical Research Council Adult and Children's Leukaemia Working Parties. Blood 1998, 92, 2322-2333.

10. Breems, D.A.; van Putten, W.L.; de Greef, G.E.; van Zelderen-Bhola, S.L.; Gerssen-Schoorl, K.B.; Mellink, C.H.; Nieuwint, A.; Jotterand, M.; Hagemeijer, A.; Beverloo, H.B.; et al. Monosomal karyotype in acute myeloid leukemia: A better indicator of poor prognosis than a complex karyotype. J. Clin. Oncol. 2008, 26, 4791-4797.

11. Medeiros, B.C.; Othus, M.; Fang, M.; Roulston, D.; Appelbaum, F.R. Prognostic impact of monosomal karyotype in young adult and elderly acute myeloid leukemia: The Southwest Oncology Group (SWOG) experience. Blood 2010, 116, 2224-2228.

12. Schlenk, R.F.; Dohner, K.; Krauter, J.; Frohling, S.; Corbacioglu, A.; Bullinger, L.; Habdank, M.; Spath, D.; Morgan, M.; Benner, A.; et al. Mutations and treatment outcome in cytogenetically normal acute myeloid leukemia. N. Engl. J. Med. 2008, 358, 1909-1918.

13. Patel, J.P.; Gonen, M.; Figueroa, M.E.; Fernandez, H.; Sun, Z.; Racevskis, J.; van Vlierberghe, P.; Dolgalev, I.; Thomas, S.; Aminova, O.; et al. Prognostic relevance of integrated genetic profiling in acute myeloid leukemia. N. Engl. J. Med. 2012, 366, 1079-1089.

14. Cairoli, R.; Beghini, A.; Grillo, G.; Nadali, G.; Elice, F.; Ripamonti, C.B.; Colapietro, P.; Nichelatti, M.; Pezzetti, L.; Lunghi, M.; et al. Prognostic impact of c-KIT mutations in core binding factor leukemias: An Italian retrospective study. Blood 2006, 107, 3463-3468.

15. Schnittger, S.; Kohl, T.M.; Haferlach, T.; Kern, W.; Hiddemann, W.; Spiekermann, K.; Schoch, C. KIT-D816 mutations in AML1-ETO-positive AML are associated with impaired event-free and overall survival. Blood 2006, 107, 1791-1799.

16. Carow, C.E.; Levenstein, M.; Kaufmann, S.H.; Chen, J.; Amin, S.; Rockwell, P.; Witte, L.; Borowitz, M.J.; Civin, C.I.; Small, D. Expression of the hematopoietic growth factor receptor FLT3 (STK-1/F1k2) in human leukemias. Blood 1996, 87, 1089-1096.

17. Renneville, A.; Roumier, C.; Biggio, V.; Nibourel, O.; Boissel, N.; Fenaux, P.; Preudhomme, C. Cooperating gene mutations in acute myeloid leukemia: A review of the literature. Leukemia 2008, 22, 915-931.

18. Griffith, J.; Black, J.; Faerman, C.; Swenson, L.; Wynn, M.; Lu, F.; Lippke, J.; Saxena, K. The structural basis for autoinhibition of FLT3 by the juxtamembrane domain. Mol. Cell 2004, 13, 169-178.

19. Small, D. FLT3 Mutations: Biology and Treatment. Hematology 2006, 2006, 178-84.

20. Levis, M.; Murphy, K.M.; Pham, R.; Kim, K.T.; Stine, A.; Li, L.; McNiece, I.; Smith, B.D.; Small, D. Internal tandem duplications of the FLT3 gene are present in leukemia stem cells. Blood 2005, 106, 673-680.

21. Shih, L.Y.; Huang, C.F.; Wu, J.H.; Lin, T.L.; Dunn, P.; Wang, P.N.; Kuo, M.C.; Lai, C.L.; Hsu, H.C. Internal tandem duplication of FLT3 in relapsed acute myeloid leukemia: A comparative analysis of bone marrow samples from 108 adult patients at diagnosis and relapse. Blood 2002, 100, 2387-2392. 
22. Shih, L.Y.; Huang, C.F.; Wu, J.H.; Wang, P.N.; Lin, T.L.; Dunn, P.; Chou, M.C.; Kuo, M.C.; Tang, C.C. Heterogeneous patterns of FLT3 Asp(835) mutations in relapsed de novo acute myeloid leukemia: A comparative analysis of 120 paired diagnostic and relapse bone marrow samples. Clin. Cancer Res. 2004, 10, 1326-1332.

23. Swords, R.; Freeman, C.; Giles, F. Targeting the FMS-like tyrosine kinase 3 in acute myeloid leukemia. Leukemia 2012, 26, 2176-2185.

24. Borthakur, G.; Kantarjian, H.; Ravandi, F.; Zhang, W.; Konopleva, M.; Wright, J.J.; Faderl, S.; Verstovsek, S.; Mathews, S.; Andreeff, M.; Cortes, J.E. Phase I study of sorafenib in patients with refractory or relapsed acute leukemias. Haematologica 2011, 96, 62-68.

25. Fischer, T.; Stone, R.M.; Deangelo, D.J.; Galinsky, I.; Estey, E.; Lanza, C.; Fox, E.; Ehninger, G.; Feldman, E.J.; Schiller, G.J.; et al. Phase IIB trial of oral Midostaurin (PKC412), the FMS-like tyrosine kinase 3 receptor (FLT3) and multi-targeted kinase inhibitor, in patients with acute myeloid leukemia and high-risk myelodysplastic syndrome with either wild-type or mutated FLT3. J. Clin. Oncol. 2010, 28, 4339-4345.

26. Smith, B.D.; Levis, M.; Beran, M.; Smith, B.D.; Giles, F.; Kantarjian, H.; Berg, K.; Murphy, K.M.; Dauses, T.; Allebach, J.; Small, D.; et al. Single-agent CEP-701, a novel FLT3 inhibitor, shows biologic and clinical activity in patients with relapsed or refractory acute myeloid leukemia. Blood 2004, 103, 3669-3676.

27. Knapper, S.; Burnett, A.K.; Littlewood, T.; Kell, W.J.; Agrawal, S.; Chopra, R.; Clark, R.; Levis, M.J.; Small, D. A phase 2 trial of the FLT3 inhibitor lestaurtinib (CEP701) as first-line treatment for older patients with acute myeloid leukemia not considered fit for intensive chemotherapy. Blood 2006, 108, 3262-3270.

28. Cortes, J.; Foran, J.; Ghirdaladze, D.; de Vetten, M.P.; Zodelava, M.; Holman, P.; Levis, M.J.; Kantarjian, H.M.; Borthakur, G.; James, J.; et al. AC220, a Potent, Selective, Second Generation FLT3 Receptor Tyrosine Kinase (RTK) Inhibitor, in a First-in-Human (FIH) Phase 1 AML Study. Blood (ASH Annual Meeting Abstracts) 2009, 114, 636.

29. Fenaux, P.; Mufti, G.J.; Hellstrom-Lindberg, E.; Santini, V.; Gattermann, N.; Germing, U.; Sanz, G.; List, A.F.; Gore, S.; Seymour, J.F.; et al. Azacitidine prolongs overall survival compared with conventional care regimens in elderly patients with low bone marrow blast count acute myeloid leukemia. J. Clin. Oncol. 2010, 28, 562-569.

30. Kantarjian, H.M.; Thomas, X.G.; Dmoszynska, A.; Wierzbowska, A.; Mazur, G.; Mayer, J.; Gau, J.P.; Chou, W.C.; Buckstein, R.; Cermak, J.; et al. Multicenter, Randomized, Open-Label, Phase III Trial of Decitabine versus Patient Choice, With Physician Advice, of Either Supportive Care or Low-Dose Cytarabine for the Treatment of Older Patients with Newly Diagnosed Acute Myeloid Leukemia. J. Clin. Oncol. 2012, 30, 2670-2677.

31. Assouline, S.; Culjkovic, B.; Cocolakis, E.; Rousseau, C.; Beslu, N.; Amri, A.; Caplan, S.; Leber, B.; Roy, D.C.; Miller, W.H., Jr.; Borden, K.L. Molecular targeting of the oncogene eIF4E in acute myeloid leukemia (AML): A proof-of-principle clinical trial with ribavirin. Blood 2009, 114, $257-260$. 
32. Rizzieri, D.A.; Feldman, E.; Dipersio, J.F.; Gabrail, N.; Stock, W.; Strair, R.; Rivera, V.M.; Albitar, M.; Bedrosian, C.L.; Giles, F.J. A phase 2 clinical trial of deforolimus (AP23573, MK-8669), a novel mammalian target of rapamycin inhibitor, in patients with relapsed or refractory hematologic malignancies. Clin. Cancer Res. 2008, 14, 2756-2762.

33. Cortes, J.E.; Feldman, E.J.; Yee, K.; Rizzieri, D.A.; Advani, A.S.; Charman, A.; Martin, J.; Kantarjian, H.M. Results of the OPAL Study: A Phase II Study to Evaluate the Efficacy, Safety and Tolerability of Tosedostat (CHR-2797) in Elderly Subjects with Treatment Refractory or Relapsed Acute Myeloid Leukemia. Blood (ASH Annual Meeting Abstracts) 2011, 118, 767.

34. Sievers, E.L.; Larson, R.A.; Stadtmauer, E.A.; Estey, E.; Lowenberg, B.; Dombret, H.; Karanes, C.; Theobald, M.; Bennett, J.M.; Sherman, M.L.; et al. Efficacy and safety of gemtuzumab ozogamicin in patients with CD33-positive acute myeloid leukemia in first relapse. J. Clin. Oncol. 2001, 19, 3244-3254.

35. Karp, J.E.; Lancet, J.E.; Kaufmann, S.H.; End, D.W.; Wright, J.J.; Bol, K.; Horak, I.; Tidwell, M.L.; Liesveld, J.; Kottke, T.J.; et al. Clinical and biologic activity of the farnesyltransferase inhibitor R115777 in adults with refractory and relapsed acute leukemias: A phase 1 clinical-laboratory correlative trial. Blood 2001, 97, 3361-3369.

36. Levis, M.; Ravandi, F.; Wang, E.S.; Baer, M.R.; Perl, A.; Coutre, S.; Erba, H.; Stuart, R.K.; Baccarani, M.; Cripe, L.D.; et al. Results from a randomized trial of salvage chemotherapy followed by lestaurtinib for patients with FLT3 mutant AML in first relapse. Blood 2011, 117, 3294-3301.

37. Pratz, K.W.; Sato, T.; Murphy, K.M.; Stine, A.; Rajkhowa, T.; Levis, M. FLT3-mutant allelic burden and clinical status are predictive of response to FLT3 inhibitors in AML. Blood 2010, 115, 1425-1432.

38. Sato, T.; Yang, X.; Knapper, S.; White, P.; Smith, B.D.; Galkin, S.; Small, D.; Burnett, A.; Levis, M. FLT3 ligand impedes the efficacy of FLT3 inhibitors in vitro and in vivo. Blood 2011, 117, 3286-3293.

39. Galm, O.; Herman, J.G.; Baylin, S.B. The fundamental role of epigenetics in hematopoietic malignancies. Blood Rev. 2006, 20, 1-13.

40. Herman, J.G.; Baylin, S.B. Gene silencing in cancer in association with promoter hypermethylation. N. Engl. J. Med. 2003, 349, 2042-2054.

41. Fazi, F.; Zardo, G.; Gelmetti, V.; Travaglini, A.; Ciolfi, A.; di Croce, L.; Rosa, A.; Bozzoni, I.; Grignani, F.; Lo-Coco, F.; et al. Heterochromatic gene repression of the retinoic acid pathway in acute myeloid leukemia. Blood 2007, 109, 4432-4440.

42. Oki, Y.; Aoki, E.; Issa, J.P. Decitabine-bedside to bench. Crit. Rev. Oncol. Hematol. 2007, 61, 140-152.

43. Reuveni, Y.; Rosenthal, L.J. Effect of 5-azacytidine on cytoplasmic ribosomal and messenger ribonucleic acids in BSC-1 cells. Antimicrob. Agents Chemother. 1979, 15, 235-239.

44. Cohen, M.B.; Glazer, R.I. Comparison of the cellular and RNA-dependent effects of sangivamycin and toyocamycin in human colon carcinoma cells. Mol. Pharmacol. 1985, 27, 349-355.

45. Glazer, R.I.; Peale, A.L.; Beisler, J.A.; Abbasi, M.M. The effect of 5-azacytidine and dihydro-5-azacytidine on nuclear ribosomal RNA and poly(A) RNA synthesis in L1210 cells in vitro. Mol. Pharmacol. 1980, 17, 111-117. 
46. Figueroa, M.E.; Lugthart, S.; Li, Y.; Erpelinck-Verschueren, C.; Deng, X.; Christos, P.J.; Schifano, E.; Booth, J.; van Putten, W.; Skrabanek, L.; et al. DNA methylation signatures identify biologically distinct subtypes in acute myeloid leukemia. Cancer Cell 2010, 17, 13-27.

47. Stimson, L.; Wood, V.; Khan, O.; Fotheringham, S.; la Thangue, N.B. HDAC inhibitor-based therapies and haematological malignancy. Ann. Oncol. 2009, 20, 1293-1302.

48. Raffoux, E.; Cras, A.; Recher, C.; Boelle, P.Y.; de Labarthe, A.; Turlure, P.; Marolleau, J.P.; Reman, O.; Gardin, C.; Victor, M.; et al. Phase 2 clinical trial of 5-azacitidine, valproic acid, and all-trans retinoic acid in patients with high-risk acute myeloid leukemia or myelodysplastic syndrome. Oncotarget 2010, 1, 34-42.

49. Garcia-Manero, G.; Kantarjian, H.M.; Sanchez-Gonzalez, B.; Yang, H.; Rosner, G.; Verstovsek, S.; Rytting, M.; Wierda, W.G.; Ravandi, F.; Koller, C.; et al. Phase 1/2 study of the combination of 5-aza-2'-deoxycytidine with valproic acid in patients with leukemia. Blood 2006, 108, 3271-3279.

50. Xu, Q.; Simpson, S.E.; Scialla, T.J.; Bagg, A.; Carroll, M. Survival of acute myeloid leukemia cells requires PI3 kinase activation. Blood 2003, 102, 972-980.

51. Kornblau, S.M.; Womble, M.; Qiu, Y.H.; Jackson, C.E.; Chen, W.; Konopleva, M.; Estey, E.H.; Andreeff, M. Simultaneous activation of multiple signal transduction pathways confers poor prognosis in acute myelogenous leukemia. Blood 2006, 108, 2358-2365.

52. Borden, K.L.; Culjkovic-Kraljacic, B. Ribavirin as an anti-cancer therapy: Acute myeloid leukemia and beyond? Leuk. Lymphoma 2010, 51, 1805-1815.

53. Kraljacic, B.C.; Arguello, M.; Amri, A.; Cormack, G.; Borden, K. Inhibition of eIF4E with ribavirin cooperates with common chemotherapies in primary acute myeloid leukemia specimens. Leukemia 2011, 25, 1197-1200.

54. Topisirovic, I.; Guzman, M.L.; McConnell, M.J.; Licht, J.D.; Culjkovic, B.; Neering, S.J.; Jordan, C.T.; Borden, K.L. Aberrant eukaryotic translation initiation factor 4E-dependent mRNA transport impedes hematopoietic differentiation and contributes to leukemogenesis. Mol. Cell. Biol. 2003, 23, 8992-9002.

55. Fukunaga, R.; Hunter, T. MNK1, a new MAP kinase-activated protein kinase, isolated by a novel expression screening method for identifying protein kinase substrates. EMBO J. 1997, 16,1921-1933.

56. Waskiewicz, A.J.; Flynn, A.; Proud, C.G.; Cooper, J.A. Mitogen-activated protein kinases activate the serine/threonine kinases Mnk1 and Mnk2. EMBO J. 1997, 16, 1909-1920.

57. Waskiewicz, A.J.; Johnson, J.C.; Penn, B.; Mahalingam, M.; Kimball, S.R.; Cooper, J.A. Phosphorylation of the cap-binding protein eukaryotic translation initiation factor 4E by protein kinase Mnk1 in vivo. Mol. Cell. Biol. 1999, 19, 1871-1880.

58. Scheper, G.C.; Morrice, N.A.; Kleijn, M.; Proud, C.G. The mitogen-activated protein kinase signal-integrating kinase Mnk2 is a eukaryotic initiation factor 4E kinase with high levels of basal activity in mammalian cells. Mol. Cell. Biol. 2001, 21, 743-754.

59. Topisirovic, I.; Ruiz-Gutierrez, M.; Borden, K.L. Phosphorylation of the eukaryotic translation initiation factor eIF4E contributes to its transformation and mRNA transport activities. Cancer Res. 2004, 64, 8639-8642.

60. Kentsis, A.; Topisirovic, I.; Culjkovic, B.; Shao, L.; Borden, K.L. Ribavirin suppresses eIF4E-mediated oncogenic transformation by physical mimicry of the 7-methyl guanosine mRNA cap. Proc. Natl. Acad. Sci. USA 2004, 101, 18105-18110. 
61. Graff, J.R.; Konicek, B.W.; Vincent, T.M.; Lynch, R.L.; Monteith, D.; Weir, S.N.; Schwier, P.; Capen, A.; Goode, R.L.; Dowless, M.S.; et al. Therapeutic suppression of translation initiation factor eIF4E expression reduces tumor growth without toxicity. J. Clin. Invest. 2007, 117, 2638-2648.

62. Kentsis, A.; Volpon, L.; Topisirovic, I.; Soll, C.E.; Culjkovic, B.; Shao, L.; Borden, K.L. Further evidence that ribavirin interacts with eIF4E. RNA 2005, 11, 1762-1766.

63. Assouline, S.; Kraljacic-Culjkovic, B.; Cocolakis, E.; Amri, A.; Bergeron, J.; Jamal, R.; Miller, W.H., Jr.; Borden, K.L.B. A Phase I Combination Study of Ribavirin and Low Dose Cytarabine Arabinoside (ara-C) in M4/M5 Acute Myeloid Leukemia (AML) and AML with High eIF4E. Blood (ASH Annual Meeting Abstracts) 2011, 118, 3606.

64. Kojima, K.; Shimanuki, M.; Shikami, M.; Samudio, I.J.; Ruvolo, V.; Corn, P.; Hanaoka, N.; Konopleva, M.; Andreeff, M.; Nakakuma, H. The dual PI3 kinase/mTOR inhibitor PI-103 prevents p53 induction by Mdm2 inhibition but enhances p53-mediated mitochondrial apoptosis in p53 wild-type AML. Leukemia 2008, 22, 1728-1736.

65. Park, S.; Chapuis, N.; Bardet, V.; Tamburini, J.; Gallay, N.; Willems, L.; Knight, Z.A.; Shokat, K.M.; Azar, N.; Viguie, F.; et al. PI-103, a dual inhibitor of Class IA phosphatidylinositide 3-kinase and mTOR, has antileukemic activity in AML. Leukemia 2008, 22, 1698-1706.

66. Alam, M.M.; Joh, E.H.; Kim, Y.; Oh, Y.I.; Hong, J.; Kim, B.; Kim, D.H.; Lee, Y.S. Synthesis and biological evaluation of cyclopentane-linked alkyl phosphocholines as potential anticancer agents that act by inhibiting Akt phosphorylation. Eur. J. Med. Chem. 2012, 47, 485-492.

67. Rahmani, M.; Anderson, A.; Habibi, J.R.; Crabtree, T.R.; Mayo, M.; Harada, H.; Ferreira-Gonzalez, A.; Dent, P.; Grant, S. The BH3-only protein Bim plays a critical role in leukemia cell death triggered by concomitant inhibition of the PI3K/Akt and MEK/ERK1/2 pathways. Blood 2009, 114, 4507-4516.

68. Yee, K.W.; Zeng, Z.; Konopleva, M.; Verstovsek, S.; Ravandi, F.; Ferrajoli, A.; Thomas, D.; Wierda, W.; Apostolidou, E.; Albitar, M.; et al. Phase I/II study of the mammalian target of rapamycin inhibitor everolimus (RAD001) in patients with relapsed or refractory hematologic malignancies. Clin. Cancer. Res. 2006, 12, 5165-5173.

69. Xu, Q.; Thompson, J.E.; Carroll, M. mTOR regulates cell survival after etoposide treatment in primary AML cells. Blood 2005, 106, 4261-4268.

70. Chapuis, N.; Tamburini, J.; Green, A.S.; Vignon, C.; Bardet, V.; Neyret, A.; Pannetier, M.; Willems, L.; Park, S.; Macone, A.; et al. Dual inhibition of PI3K and mTORC1/2 signaling by NVP-BEZ235 as a new therapeutic strategy for acute myeloid leukemia. Clin. Cancer. Res. 2010, $16,5424-5435$.

71. Amadori, S.; Stasi, R.; Martelli, A.M.; Venditti, A.; Meloni, G.; Pane, F.; Martinelli, G.; Lunghi, M.; Pagano, L.; Cilloni, D.; et al. Temsirolimus, an mTOR inhibitor, in combination with lower-dose clofarabine as salvage therapy for older patients with acute myeloid leukaemia: Results of a phase II GIMEMA study (AML-1107). Br. J. Haematol. 2012, 156, 205-212.

72. Perl, A.E.; Kasner, M.T.; Tsai, D.E.; Vogl, D.T.; Loren, A.W.; Schuster, S.J.; Porter, D.L.; Stadtmauer, E.A.; Goldstein, S.C.; Frey, N.V.; et al. A phase I study of the mammalian target of rapamycin inhibitor sirolimus and MEC chemotherapy in relapsed and refractory acute myelogenous leukemia. Clin. Cancer Res. 2009, 15, 6732-6739. 
73. Krige, D.; Needham, L.A.; Bawden, L.J.; Flores, N.; Farmer, H.; Miles, L.E.; Stone, E.; Callaghan, J.; Chandler, S.; Clark, V.L.; et al. CHR-2797: An antiproliferative aminopeptidase inhibitor that leads to amino acid deprivation in human leukemic cells. Cancer Res. 2008, 68, 6669-6679.

74. Hamann, P.R.; Hinman, L.M.; Beyer, C.F.; Lindh, D.; Upeslacis, J.; Flowers, D.A.; Bernstein, I. An anti-CD33 antibody-calicheamicin conjugate for treatment of acute myeloid leukemia. Choice of linker. Bioconjug. Chem. 2002, 13, 40-46.

75. Griffin, J.D.; Linch, D.; Sabbath, K.; Larcom, P.; Schlossman, S.F. A monoclonal antibody reactive with normal and leukemic human myeloid progenitor cells. Leuk. Res. 1984, 8, 521-534.

76. Bross, P.F.; Beitz, J.; Chen, G.; Chen, X.H.; Duffy, E.; Kieffer, L.; Roy, S.; Sridhara, R.; Rahman, A.; Williams, G.; Pazdur, R. Approval summary: Gemtuzumab ozogamicin in relapsed acute myeloid leukemia. Clin. Cancer Res 2001, 7, 1490-1496.

77. Petersdorf, S.; Kopecky, K.; Stuart, R.K.; Larson, R.A.; Nevill, T.J.; Stenke, L.; Slovak, M.L.; Tallman, M.S.; Willman, C.L.; Erba, H.; et al. Preliminary Results of Southwest Oncology Group Study S0106: An International Intergroup Phase 3 Randomized Trial Comparing the Addition of Gemtuzumab Ozogamicin to Standard Induction Therapy versus Standard Induction Therapy Followed by a Second Randomization to Post-Consolidation Gemtuzumab Ozogamicin versus No Additional Therapy for Previously Untreated Acute Myeloid Leukemia. Blood (ASH Annual Meeting Abstracts) 2009, 114, 790.

78. U.S. Food and Drug Administration. Available online: http://www.fda.gov/ (accessed on 28 September 2012).

79. Burnett, A.K.; Hills, R.K.; Milligan, D.; Kjeldsen, L.; Kell, J.; Russell, N.H.; Yin, J.A.; Hunter, A.; Goldstone, A.H.; Wheatley, K. Identification of patients with acute myeloblastic leukemia who benefit from the addition of gemtuzumab ozogamicin: Results of the MRC AML15 trial. J. Clin. Oncol. 2011, 29, 369-377.

80. Burnett, A.K.; Russell, N.H.; Hills, R.K.; Kell, J.; Freeman, S.; Kjeldsen, L.; Hunter, A.E.; Yin, J.; Craddock, C.F.; Dufva, I.H.; et al. Addition of Gemtuzumab Ozogamicin to Induction Chemotherapy Improves Survival in Older Patients with Acute Myeloid Leukemia. J. Clin. Oncol. 2012, doi:10.1200/JCO.2012.42.2964.

81. Castaigne, S.; Pautas, C.; Terre, C.; Raffoux, E.; Bordessoule, D.; Bastie, J.N.; Legrand, O.; Thomas, X.; Turlure, P.; Reman, O.; et al. Effect of gemtuzumab ozogamicin on survival of adult patients with de-novo acute myeloid leukaemia (ALFA-0701): A randomised, open-label, phase 3 study. Lancet 2012, 379, 1508-1516.

82. Walter, R.B.; Appelbaum, F.R.; Tallman, M.S.; Weiss, N.S.; Larson, R.A.; Estey, E.H. Shortcomings in the clinical evaluation of new drugs: Acute myeloid leukemia as paradigm. Blood 2010, 116, 2420-2428.

83. Hills, R.K.; Burnett, A.K. Applicability of a "Pick a Winner" trial design to acute myeloid leukemia. Blood 2011, 118, 2389-2394.

84. Uy, G.L.; Rettig, M.P.; Motabi, I.H.; McFarland, K.; Trinkaus, K.M.; Hladnik, L.M.; Kulkarni, S.; Abboud, C.N.; Cashen, A.F.; Stockerl-Goldstein, K.E.; et al. A phase $1 / 2$ study of chemosensitization with the CXCR4 antagonist plerixafor in relapsed or refractory acute myeloid leukemia. Blood 2012, 119, 3917-3924. 
85. DiPersio, J.F.; Micallef, I.N.; Stiff, P.J.; Bolwell, B.J.; Maziarz, R.T.; Jacobsen, E.; Nademanee, A.; McCarty, J.; Bridger, G.; Calandra, G. Phase III prospective randomized double-blind placebo-controlled trial of plerixafor plus granulocyte colony-stimulating factor compared with placebo plus granulocyte colony-stimulating factor for autologous stem-cell mobilization and transplantation for patients with non-Hodgkin's lymphoma. J. Clin. Oncol. 2009, 27, 4767-4773.

86. DiPersio, J.F.; Stadtmauer, E.A.; Nademanee, A.; Micallef, I.N.; Stiff, P.J.; Kaufman, J.L.; Maziarz, R.T.; Hosing, C.; Fruehauf, S.; Horwitz, M.; et al. Plerixafor and G-CSF versus placebo and G-CSF to mobilize hematopoietic stem cells for autologous stem cell transplantation in patients with multiple myeloma. Blood 2009, 113, 5720-5726.

87. Nervi, B.; Ramirez, P.; Rettig, M.P.; Uy, G.L.; Holt, M.S.; Ritchey, J.K.; Prior, J.L.; Piwnica-Worms, D.; Bridger, G.; Ley, T.J.; et al. Chemosensitization of acute myeloid leukemia (AML) following mobilization by the CXCR4 antagonist AMD3100. Blood 2009, 113, 6206-6214.

88. Feldman, E.J.; Lancet, J.E.; Kolitz, J.E.; Ritchie, E.K.; Roboz, G.J.; List, A.F.; Allen, S.L.; Asatiani, E.; Mayer, L.D.; Swenson, C.; Louie, A.C. First-in-man study of CPX-351: A liposomal carrier containing cytarabine and daunorubicin in a fixed 5:1 molar ratio for the treatment of relapsed and refractory acute myeloid leukemia. J. Clin. Oncol. 2011, 29, 979-985.

89. Lancet, J.E.; Cortes, J.E.; Kovacsovics, T.; Hogge, D.; Kolitz, J.E.; Tallman, M.S.; Chiarella, M.; Louie, A.C.; Feldman, E.J. Safety and Efficacy Sub Analysis of Secondary AML (sAML) Patients Randomized to Study 204: CPX-351 vs. Cytarabine+ DaunorubicinTherapy ( $7+3$ Regimen) in Newly Diagnosed Elderly AML Patients Aged 60-75. J. Clin. Oncol. 2011, 29, Abstract 6519.

90. Karp, J.E.; Vener, T.I.; Raponi, M.; Ritchie, E.K.; Smith, B.D.; Gore, S.D.; Morris, L.E.; Feldman, E.J.; Greer, J.M.; Malek, S.; et al. Multi-institutional phase 2 clinical and pharmacogenomic trial of tipifarnib plus etoposide for elderly adults with newly diagnosed acute myelogenous leukemia. Blood 2012, 119, 55-63.

91. Harousseau, J.L.; Martinelli, G.; Jedrzejczak, W.W.; Brandwein, J.M.; Bordessoule, D.; Masszi, T.; Ossenkoppele, G.J.; Alexeeva, J.A.; Beutel, G.; Maertens, J.; et al. A randomized phase 3 study of tipifarnib compared with best supportive care, including hydroxyurea, in the treatment of newly diagnosed acute myeloid leukemia in patients 70 years or older. Blood 2009, 114, 1166-1173.

(C) 2012 by the authors; licensee MDPI, Basel, Switzerland. This article is an open access article distributed under the terms and conditions of the Creative Commons Attribution license (http://creativecommons.org/licenses/by/3.0/). 